\title{
IDENTIDADE CULTURAL E FORMAÇÃO INDIVIDUAL: A ALEMANHA DO SÉCULO XIX E A FUNDAÇÃO DA PEDAGOGIA MODERNA
}

\author{
FABIANO DE LEMOS BRITTO*
}

\begin{abstract}
RESUMO: As origens da moderna pedagogia e sua reverberação no interior das mais recentes teorias da educação nos remetem ao modelo alemão, que se articula duplamente: como prática derivada de uma série de condições socioculturais específicas e como sistema conceitual, na medida em que responde a uma nova concepção de liberdade humana surgida no limiar do pensamento moderno. Este artigo pretende avaliar os imbricamentos entre essas duas dimensões.
\end{abstract}

Palavras-chave: História da pedagogia. Filosofia da educação. Neo-humanismo. Bildung.

\section{Cultural identity and individual formation: Germany in $19^{\mathrm{TH}}$ CENTURY AND THE FOUNDATION OF MODERN PEDAGOGY}

ABSTRACT: The origins of modern pedagogy and its reverberation within the most recent education theories leads us backwards to German model, that articulates itself in two ways: as a set of pragmatic actions, derived from a series of social and cultural conditions, and as conceptual system, as long as it responds to a new conception of human freedom that came up in the beginning of modern thought. This paper intends to evaluate the imbrications between those two dimensions.

Key words: History of pedagogy. Philosophy of education. Neo-humanism. Bildung.

Doutor em Filosofia e professor do Departamento de Filosofia da Universidade do Estado do Rio de Janeiro (Uerj). E-mail: fabianolemos@gmail.com 


\section{IDENTITÉ CULTURELLE ET FORMATION INDIVIDUELLE: L'ALLEMAGNE} AU XIX ${ }^{\text {EME }}$ SIÉCLE ET LA FONDATION DE LA PÉDAGOGIE MODERNE

RÉSUMÉ: Les origines de la pédagogie moderne et sa réverbération dans les théories les plus récentes de l'éducation nous renvoient au modèle allemand, qui s'articule doublement: comme pratique issue d'une série de conditions socio-culturelles spécifiques et comme système conceptuel, dans la mesure où il répond à une nouvelle conception de liberté humaine surgie au seuil de la pensée moderne. Cet article vise à évaluer les imbrications de ces deux dimensions.

Mots-clés: Histoire de la pédagogie. Philosophie de l'éducation. Néo-humanisme. Bildung.

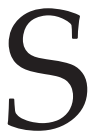

eparados pelo intervalo de mais de um século, dois jovens alemães refletem sobre a forma como seus destinos estavam inscritos nos limites de sua educação, sobre como a fortuna ou a tragédia de suas vidas se enraizava nesse solo, para eles ainda tão recente, de sua formação escolar - e articulam, desse modo, uma crítica extremamente precisa do significado da ideia de cultura promovida no interior das instituições de ensino.

O primeiro deles é o personagem título de Os sofrimentos do jovem Werther, que Goethe publicara pela primeira vez no final do século XVIII, e que se tornou, nas décadas seguintes, síntese simbólica de toda uma geração que, informada pelo ímpeto com que a Revolução Francesa varreu da Europa suas antigas concepções ideológicas, ergueu para si o direito de uma nova cultura, de uma nova política, mas, sobretudo, de uma nova forma de pensar. Werther volta-se com desgosto para os anos que passara na escola: ali, ele diz, ele sofrera de todas "as limitações que aprisionam a capacidade humana de ação e pesquisa", e, contrariado, percebe que "toda a atividade se esgota na satisfação de necessidades cujo único propósito é prolongar nossa pobre existência" (Goethe, 1850-1851, p. 154). As incisivas declarações deste estudante poderiam ser tomadas como simples exaltação romântica de um jovem idealista, mas isso se não levássemos em consideração dois fatos importantes: o primeiro, que a voz de Werther fazia soar uma crítica absolutamente recorrente e típica entre os jovens de seu tempo, como podemos constatar nos estatutos das agremiações estudantis que nasciam nesse período (cf. Eyck, 1955, passim). Em segundo lugar, o fato de que era personagem de Goethe indica até que ponto suas críticas ficcionais funcionam como duplo das críticas bastante concretas que seu autor, como influente intelectual, havia dirigido aos estabelecimentos de ensino da Europa como um todo, mas, em particular, da Prússia. É preciso lembrar que Goethe não apenas transitou frequentemente pelo eixo erudito da Europa clássica - em suas viagens à Itália e à França, por exemplo -, elaborando uma concepção de cultura universalista, pan-nacionalista que pode ser observada em seus escritos sobre arte. A insatisfação 
de seu Werther era, portanto, o ponto de partida de uma reformulação concreta dos princípios da cultura e das instituições de ensino a ela vinculadas.

Em 1906, era a vez de outro estudante, o jovem Törless, personagem de Robert Musil, avaliar com temor seus anos escolares. Törless, que sonhava com Kant, mas não conseguia compreendê-lo, não podia deixar de sofrer com a possibilidade de que a promiscuidade e a leviandade de ares benevolentes da escola secundária se estendessem para o resto de sua vida - "Essa vida silenciosa me oprimia, me sufocava e cada vez mais me obrigava a encará-la. Sofri com medo de que toda a nossa vida fosse assim e que só aqui e ali, fragmentadamente, eu soubesse disso..." (Musil, 1981, p. 189). Apesar de estes receios poderem ser compreendidos como muito próximos da crítica elaborada por Goethe um século antes, a situação aqui é completamente diversa. As décadas que seguiram o Törless não viram surgir nenhum tipo de esforço no sentido de ampliar as fronteiras da cultura ou de reinserir na estrutura burocrática de ensino a ideia de liberdade. Muito pelo contrário, os anos seguintes à publicação de Musil apenas testemunharam o avanço das duas grandes guerras mundiais, a destruição sistemática de toda e qualquer forma de humanismo no interior das instituições de ensino e a substituição de uma cultura da integração, cujo modelo era a arte goethiana, por uma cultura da homogeneização, cuja matriz não poderia ser outra senão a ideologia da violência fascista. Sintomaticamente, Robert Musil foi uma das vítimas desse processo político de empobrecimento cultural da primeira metade do século XX - longe de desfrutar a fama e o sucesso editorial de Goethe, ele morreu esquecido, mergulhado em dívidas e extenuado pelo trabalho que tinha de produzir em jornais a fim de sobreviver. Sua crítica ao projeto ideológico da educação que lhe era contemporâneo foi exemplarmente silenciada por uma sociedade ocupada em transformar, progressivamente, suas instituições culturais em aparelhos de perpetuação ideológica, esvaziando-lhes de qualquer caráter crítico. A melancolia de seu Törless era, assim, o sintoma de uma falência, o ponto de chegada de uma ideologia que, por diversas vias, havia integrado ao cosmopolitismo uma defesa cada vez mais insistente em um nacionalismo ressentido, e que transformara o humanismo em uma moeda de troca comercial.

Ora, o arco que cobre esses dois momentos, entre a insatisfação revoltada de Werther e a melancolia temerosa de Törless, circunscreve precisamente o período de modernização da cultura alemã, e, mais fundamentalmente, a trajetória de um modelo pedagógico que influenciou - e influencia, ainda hoje - não apenas o imaginário germânico, mas, amplamente, toda a ideia de educação contemporânea. Entre Goethe e Musil, o que se desenha é um projeto ao mesmo tempo estrutural, concreto e conceitual: de modo incontornável, o problema da formação da identidade cultural, problema que, em última análise, era o motivo da angústia existencial de seus personagens, apresenta-se como o vínculo entre o desenvolvimento de uma nova forma 
de consciência - burguesa, poderíamos dizer, com Marx, mas, sobretudo, individual - e a reflexão crítica sobre as condições concretas onde essa consciência pode se dar. Ou seja, pela primeira vez na história da pedagogia ocidental é sistematizada a ideia de que as instituições de ensino não devem apenas, por meio de certas práticas espirituais e certos condicionamentos físicos, adequar a natureza dos indivíduos a uma concepção de cultura predeterminada (por Deus, pelo rei ou pela ideia horizontal de um caráter único da espécie humana). Agora, é a cultura que deve revelar-se como resultado do desenvolvimento otimizado das potencialidades interiores das consciências dos indivíduos. Por que essa compreensão é fundadora da pedagogia moderna, e sob que condições históricas e institucionais ela pôde ter lugar na Alemanha do século XIX, é o que eu gostaria de avaliar aqui em linhas gerais.

Um novo equilíbrio entre a interioridade dos sujeitos e a exterioridade das instituições sociais no processo de formação da identidade cultural havia sido obtido no começo do século XIX na Alemanha, no interior de um movimento de reforma, filosófica e política, que alterou profundamente tanto o conteúdo referencial do imaginário alemão quanto a forma concreta de suas estruturas sociais, e que se fez conhecer como neo-humanismo. A imensa amplitude das reformas neo-humanistas foi precisamente o que lhe garantiu o estatuto de momento fundador na história da pedagogia moderna, assim como a efetividade de seus resultados perpetuou, em maior ou menor grau, sua constante influência sobre os sistemas educacionais que lhe seguiram. Mas a universalidade do projeto germânico moderno não deve esconder suas raízes sociais extremamente singulares - e nada arbitrárias. O conceito de Bildung, de uma educação que partia do âmbito individual, e que norteou suas propostas de renovação espiritual e material da cultura, emerge no horizonte da história alemã como resposta a uma situação político-social que já há muito apresentava sintomas de falência. A Bildung, tanto em um nível psicológico quanto em um nível institucional, foi o que permitiu aos alemães, pela primeira vez, resgatar certa unidade simbólica, uma imagem como nação. Somente a ideia de uma cultura que nasce dos indivíduos e que se estende sob a forma de um espírito popular, um Volksgeist, parecia ter força ideológica suficiente para recuperar uma identidade cultural que para a Alemanha, como uma série de estados independentes e gradualmente fragmentados, era particularmente difícil.

É verdade que, até o final do século XVIII, não havia na Alemanha nenhuma intenção enfática de consolidar propriamente um sistema de ensino. Mudanças estruturais que vinham sendo observadas há alguns anos no resto da Europa em relação à escola, por exemplo - uma relativa socialização dos currículos, um esforço de padronização dos procedimentos de avaliação e dos critérios de divisão dos alunos -, ainda encontravam grande resistência numa sociedade em que os primeiros efeitos do progresso industrial demoraram a surgir. De modo geral - mesmo que 
com algumas exceções em regiões mais progressistas, como Berlim ou alguns estados austríacos - os estabelecimentos de ensino distribuíam-se ainda segundo o antigo modelo medieval: educação técnico-profissional e religiosa para os pobres, universidades dominadas pelas cadeiras teológicas para os nobres. Além disso, no caso das faculdades e da formação de uma classe de eruditos, uma Gelehrsamkeit, nos meios universitários, a influência do sistema francês, apoiada e incentivada pelo Estado, coibiu o aparecimento de uma pedagogia nacional. Frederico II, imperador dos Estados germânicos entre 1712 e 1786, aos olhos de seus contemporâneos, era um francófilo progressista, rei-filósofo forjado à maneira de Luís XIV (cf. Masseau, 1995, p. 66-74).

Essa influência fomentada do modelo francês na Alemanha teve um duplo valor. Por um lado, ela perpetuou, até certo momento, uma compreensão da educação que se voltava para o aprendizado de certa prática de convivência da nobreza e inibia o progresso das ciências que não colaborassem com esse objetivo. As observações de Michel de Montaigne nesse contexto são exemplares. Em um de seus Ensaios, intitulado "Da educação das crianças", Montaigne aconselha a uma nobre: "Senhora, a ciência é um grande ornamento e uma ferramenta de admirável utilidade, sobretudo em pessoas criadas em tal grau de fortuna, como vós o sois. $\mathrm{Na}$ verdade, em mãos vis e baixas, ela não tem sua justa utilidade" (Montaigne, 2000, p. 223). A educação univeral, portanto, não faria sentido. Não é difícil deduzir que, numa sociedade como a da Alemanha do século XVIII, onde o poder econômico da nobreza era relativamente menor ao da França - e onde os objetivos ideológicos das classes dominantes dos Estados independentes eram muitas vezes conflitantes -, a propagação desse modelo teve consequências particularmente retrógradas.

Por outro lado, foi exatamente a Revolução Francesa que parece ter incentivado, especialmente entre os intelectuais alemães, a elaboração gradualmente mais insistente de uma crítica contra os modelos vigentes da estrutura política a partir da ideia de renovação ampla da cultura. O entusiasmo com que esses alemães testemunharam, do outro lado do Reno, o ímpeto transformador dos acontecimentos que mudaram a ordem da sociedade francesa está intimamente conectado ao surgimento do neo-humanismo alguns anos mais tarde. Paradoxalmente, foi a eloquência de Marat e de Robespierre que parece ter convencido os germânicos da necessidade de se afastar do modelo cultural francófilo e de voltar os olhos para sua dinâmica interna. Uma nova identidade cultural só seria possível a partir da recusa das premissas desse modelo; a Revolução havia destruído a confiança na unidade ideológica da nobreza, que servira até então como teleologia do sistema de educação francês. $O$ que um grupo de intelectuais alemães, representados sobretudo por Wilhelm von Humboldt, percebeu, no início do século XIX, foi que a própria ideia de um telos externo no processo de formação cultural perpetuaria um esquema de dominação 
vertical onde todo aluno, todo estudante deveria ser, antes de mais nada, um súdito ou um funcionário do Estado - e os limites de seu desenvolvimento individual seriam restritos por essa força alheia, castradora, que é sempre anticrítca. O neohumanismo reage a isso com um retorno à interioridade, oferecendo o complemento positivo de um processo de falência das estruturas sociais do qual a Revolução Francesa havia sido o último e mais importante sintoma negativo. Partir do homem, daquilo que nele é mais íntimo, mais afastado da corruptibilidade dos esquemas de dominação - eis a divisa que pode definir o projeto pedagógico de Humboldt e seus contemporâneos. Os próprios franceses não conseguiram diagnosticar essa necessidade, de modo que a igualdade, a liberdade e a fraternidade se tornaram, sob o domínio de Napoleão, ideais teóricos coercitivos, que baniram dos currículos escolares qualquer coisa que não favorecesse a ideia de progresso tecnológico sustentada pela nova consciência burguesa. Por esse motivo, no que diz respeito ao sistema de ensino e às instituições culturais, a França, na passagem do século XVIII para o XIX, experimentou um processo de desaceleração e atraso que só foi contornado quase um século depois. Coube, portanto, aos alemães, menos sensíveis para os avanços do positivismo técnico e do progresso tecnológico, formular as bases de uma pedagogia efetivamente renovada.

Já me referi ao fato de que é em torno do conceito de Bildung que essa formulação se deu. Em oposição ao conceito de Kultur, que designou, a partir de então, o estado externo da cultura, suas instituições públicas, seu horizonte ideológico coletivo, a Bildung refere-se ao processo de autodesenvolvimento, de autoformação dos indivíduos no que diz respeito à sua educação. O que este termo sublinhava era a importância incontornável da dimensão ativa da individualidade no processo de formação cultural. É essa dimensão que dificilmente se deixa entrever na tradução normalmente utilizada em português, cultura - termo, que, além disso, traduz também o alemão Kultur e ignora a diferença fundamental dos dois conceitos. Poderíamos parafrasear o original, traduzindo-o como formação cultural individual. Ainda assim, isso seria insuficiente.

A preocupação com a autonomia dos indivíduos nos processos de formação cultural deu-se inicialmente em meios teóricos. Isso se deixa observar pela maneira como a palavra Bildung vai substituindo, aos poucos, nos debates intelectuais, mas também nos jornais lidos pelo grande público, outros termos utilizados anteriormente. Essa não é uma transição linguística arbitrária ou sem consequências: ela indica a transformação de um universo de referências extremamente importante para os alemães. Ao longo do século XIX - e principalmente a partir de Humboldt -, o uso da palavra Bildung constituiu-se numa espécie de unanimidade, e atualizou toda a carga semântica que ela havia recebido desde sua origem pré-pedagógica, ainda que em uma direção completamente nova em relação a ela. 
Mas essa mudança ideológica foi logo acompanhada de efeitos concretos. Na realidade, para que as propostas do neo-humanismo de Humboldt pudessem ser colocadas em discussão, e pudessem, assim, ser investidas de uma legitimidade pública, uma série de transformações na política dos Estados alemães teve de ter lugar. $\mathrm{O}$ alcance da ideia de autodesenvolvimento pretendida pelos intelectuais estendia-se incisivamente no sentido de limitar o poder da esfera de ação do poder oficial sobre os assuntos relacionados à pedagogia. Uma das dimensões políticas mais importantes do neo-humanismo - e que, ainda hoje, mostra-se particularmente problemática - é a que requer como duplo da autonomia dos sujeitos a autonomia das instituições de ensino em relação ao Estado: esta é sua condição social; e se há algum idealismo em Humboldt - e certamente há -, ele é incontornavelmente circunscrito e conduzido por essa divisa pragmática. Já nos últimos anos do século XVIII, Humboldt escreveu um de seus mais radicais textos sobre os limites do poder governamental, as Ideias para uma tentativa de determinar os limites da ação do Estado - o qual propunha a tal ponto o estreitamento do raio de ação desse poder que só veio a ser publicado postumamente, em 1851 (cf. Humboldt, 1903, p. 177). O texto inverte o fundamento do poder estatal, o equilíbrio entre liberdade pessoal e desenvolvimento social, tal como aparecia nas teorias contratualistas clássicas: ao invés de uma natureza individual que encontra seus limites na força representativa do Estado, uma reforma da política, capaz de fornecer um critério de unidade eficiente ao povo, deve dispor dessa natureza como objetivo último, e condicionar a representatividade do governo e seus bens coletivos a ela. Por isso a regra do pensamento político de Humboldt é, antes de mais nada, uma regra pedagógica, ela é a extensão pragmática de uma compreensão filosófica da natureza do homem, na medida em que reconduz o poder do Estado às exigências de seu conceito de Bildung. $\mathrm{O}$ texto sobre os limites da ação do Estado é singularmente claro quanto a isso:

\footnotetext{
A verdadeira razão não pode desejar para o homem nenhuma outra condição [Zustand] senão aquela em que não somente todo indivíduo usufrui da liberdade mais individual para desenvolver, por si mesmo, sua particularidade [Eigenthümlichkeit], mas, antes, em que também a natureza física não receba nenhuma outra forma [Gestalt] forjada pelo homem, em que todo indivíduo desse a si mesmo e voluntariamente as medidas de suas necessidades e de sua inclinação, restrito apenas pelos limites de sua força e de seu direito. (Humboldt, 1903, p. 14-15)
}

Quando, mais tarde, Humboldt escreve um relatório, a pedido do próprio governo, para estabelecer as diretrizes administrativas que orientariam a fundação da Universidade de Berlim, podemos notar como essa concepção é retomada. Ali, o critério da autonomia das faculdades é o que elas guardariam de mais fundamental: uma estrutura administrativa reformada deveria levar às últimas consequências a exigência de que o conteúdo pedagógico-científico das instituições de ensino "não 
pode ser determinado por nenhuma intenção que lhe seja externa" (Humboldt, 2002, p. 255). É importante assinalar que o fato de que essa exigência se tornou efetiva, que as diretrizes de Humboldt foram escolhidas como projeto organizacional da nova faculdade e que a Universidade de Berlim logo se tornou uma referência na Europa no que se refere à autonomia dos professores, indica que tipo de liberdade política precisou preceder o neo-humanismo, e, ao mesmo tempo, como o seu surgimento procurou radicalizá-la de acordo com uma ideia precisa de cultura e de Bildung.

Desde a última década do século anterior, a Alemanha vinha sendo submetida à desorganização e às restrições de liberdade civil de um poder estatal cada vez mais centralizador. A relativa tolerância e o visível desenvolvimento intelectual do reinado de Frederico II na Prússia deram lugar, com sua morte, em 1786, a uma época extremamente reativa neste sentido. Seu sucessor, Frederico Guilherme II, no curto período em que esteve no trono - de 1786 a 1797 -, instaurou uma política reacionária que levou a um período particularmente nebuloso para os estabelecimentos de ensino e para a consolidação de uma identidade cultural unificada: a abertura humanista que vinha se ensaiando com o Esclarecimento, a Auklärung, cedeu lugar, aos poucos, a uma administração ortodoxa, que ameaçava a autonomia e mesmo o status social e econômico do grupo de intelectuais acadêmicos, na medida em que era cada vez mais burocrática. Frederico Guilherme II instituiu um governo no qual as províncias tinham pouco poder legislativo, dando origem a um Estado que controlava todos os aspectos da vida pública. Isso acabou por destruir o projeto de um Estado esclarecido e cosmopolita e substituí-lo pela "arbitrariedade de estranhos príncipestiranos" (Holborn, 1964, p. 306), da qual, por exemplo, Kant, em 1794, havia sido uma das vítimas, quando seu escrito sobre a Religião nos limites da simples razão fora condenado pela censura de então. Em pouco tempo, a Prússia, como potência mais representativa, ao lado da Áustria, dos Estados alemães, encontrou seu isolamento diplomático e sucessivas derrotas militares.

O legado recebido pelo sucessor do trono da Prússia, Frederico Guilherme III, foi o de uma sociedade insatisfeita com sua própria imagem e gradualmente mais consciente de seu atraso cultural e tecnológico em relação aos outros países da Europa, especialmente a França. Era preciso promover uma abertura no protecionismo que havia retardado o desenvolvimento da Alemanha como nação, mas, para que essa abertura não viesse a ser interpretada como uma desintegração política do caráter nacional, foi preciso que ela viesse acompanhada da necessidade de se resgatar a identidade ideológica única do povo alemão, favorecendo a renovação das instituições por meio das quais eles procuraram constituir sua cultura. A política reformista do novo imperador foi, desse modo, a premissa histórica necessária à elaboração da pedagogia neo-humanista e de sua concepção do vínculo entre autonomia individual e independência dos sistemas de ensino. O projeto de modernização, com 
todos seus princípios elementares já amadurecidos, pôde, nas décadas seguintes, ultrapassar os limites de uma reforma ideológica para se transformar, realmente, na inauguração de um novo modelo.

Uma longa série de medidas político-institucionais tomou lugar, assim, nas duas primeiras décadas do século XIX e uma reforma estrutural profunda foi seriamente empreendida, fornecendo as bases mais permanentes do que veio a ser internacionalmente reconhecido como o modelo alemão de ensino e cultura. Gostaria de assinalar como esse modelo neo-humanista se refletiu nos três níveis de ensino que passaram a constituir o sistema educacional da Alemanha desde então, influenciando em seguida o pensamento pedagógico europeu e sendo depois incorporado mais amplamente em outras sociedades, como a americana, na passagem do século XIX para o XX.

Em primeiro lugar, o problema da educação elementar deixou de depender de uma decisão privada para se tornar uma questão pública. Aos poucos, preceptores particulares, que cuidavam de meninos e meninas em idade de alfabetização, foram sendo substituídos - embora não completamente nas regiões rurais - por uma ampla melhoria das condições da escola fundamental, a Grundschule. O maior responsável por esse avanço foi Heinrich Pestalozzi, que, ao lado de Basedow e Campe, sistematizou um projeto de formação básica universal, influenciado, sobretudo, pelo puericentrismo do Emílio, de Rousseau. O sucesso de Pestalozzi foi de tal modo eficiente que, em 1850, a erradicação do analfabetismo nas grandes cidades da Alemanha havia sido praticamente atingida. É verdade que o grupo de intelectuais a que pertencia ainda não havia articulado tão radicalmente, como Humboldt depois o faria, a ideia de autonomia da Bildung. O tipo de educação elementar definido por Pestalozzi ainda estava associado à necessidade de se obter uma função social e profissional, e condicionava o processo de formação cultural às necessidades imediatas da sociedade. Essa concepção pedagógica, que caracterizou o movimento que ficou conhecido como Philantropismus, no entanto, teve ao menos dois grandes méritos que prepararam o caminho para a efetivação do modelo humboldtiano, e, portanto, para a modernização propriamente dita das instituições pedagógicas. Ela foi a primeira responsável pelo apoio das camadas populares e pelo seu envolvimento em questões pedagógicas a partir daí, já que se instaurou precisamente lá onde essas camadas sentiam sua maior deficiência: o projeto de uma educação nacional, e, ao mesmo tempo, universal, só se firmou no momento em que surgiram as condições para um sistema de educação em larga escala. Além disso, as propostas de Pestalozzi assumiram um apelo verdadeiramente popular quando estenderam seu conceito de formação a domínios até então pouco explorados e definitivamente não estruturados. Foi neste sentido que, desde 1809, observou-se na Alemanha o surgimento de pré-escolas e creches, que acabaram ampliando o campo de atuação do processo de formação 
cultural na direção de faixas etárias cada vez mais recuadas (cf. Allen, 1986). O que o projeto pedagógico de Pestalozzi legou à pedagogia moderna foi precisamente a extensão do valor da formação cultural dos indivíduos, o modo como ele associou, à maneira de Rousseau, mas, institucionalmente, esse valor à gênese mais remota do processo de constituição da personalidade. Essa ideia foi traduzida no interior do neo-humanismo como a exigência de uma educação global, e a compreensão contemporânea das dinâmicas do aprendizado como vetores que atravessam todas as fases da vida dos indivíduos, resultando no investimento pedagógico de instituições voltadas para todo tipo de faixa etária e especificidade cultural, é diretamente devedora das reformas de Pestalozzi e de sua radicalização humboldtiana.

A segunda grande transformação empreendida nos primeiros anos do século XIX pelo novo governo alemão foi a completa reestruturação das escolas preparatórias para o ingresso nas universidades, que ficaram conhecidas desde então como Gymnasium. É verdade que esse Gymnasium, que se tornou a instituição-símbolo do neo-humanismo - podemos observá-lo na maneira como a grande maioria dos romances de formação alemães até a Segunda Guerra o têm como cenário -, surgiu na Alemanha aproximadamente no mesmo período em que os lycées de Napoleão apareciam na França, compartilhando com estes alguns ideais, estruturas e práticas de ensino. Ambos haviam sido projetados como instituição pública, humanista - na medida em que seu currículo incluía o estudo das línguas clássicas e a filosofia - e tinham por função social representar uma concepção de universalidade baseada, paradoxalmente, em moldes nacionais específicos. Ou seja, tanto o Gymnasium quanto o lycée ilustravam exemplarmente o compromisso do Estado com a educação, e deveriam fornecer a imagem de uma identidade cultural preocupada com a formação de cientistas, filósofos e artistas aptos a concorrer em igualdade com toda a inteligência europeia. É fácil perceber, por estas premissas, que não se tratava de uma instituição aberta ao povo em geral, ela se voltava para uma elite econômica e social de alunos capaz de comprometer cerca de nove anos de sua vida - duração estimada dos cursos nesse período - em função da obtenção de um grau que, pragmaticamente, tinha um valor quase tão apreciado quanto o outorgado pelas universidades. No entanto, uma diferença importante entre a escola francesa e a alemã foi responsável por uma certa prevalência desta última aos olhos de outros países europeus que também procuravam modernizar seus estabelecimentos de ensino, como a Itália e a Inglaterra, por exemplo. Ainda que os dois modelos guardassem a intenção declarada de preparar o aluno para a universidade, esse critério foi efetivado muito mais amplamente na Alemanha que na França. O Gymnasium, desse modo, agregou ao sentido humanista da educação uma dimensão fundamental da Bildung que parecia deficiente nos liceus napoleônicos: a ideia de que a formação deveria ser um processo contínuo e inteiramente justificada em si mesma. Como mostrou 
Robert Anderson em um artigo recente que compara os dois projetos, o liceu francês, relativamente mais especializado e técnico que a escola secundária alemã, ainda se inscrevia nas intenções pragmático-sociais do utilitarismo filantrópico, que o neohumanismo pretendia ultrapassar.

Obviamente, na prática, a exigência profissionalizante também ameaçou frequentemente a independência exclusivamente humanista do Gymnasium, isenta de uma teleologia prática. Isso se deu especialmente após o processo de industrialização se acelerar na Alemanha na segunda metade do século XIX e pela entrada de uma classe média emergente nos níveis mais avançados do sistema educacional. Com isso, para manter intacto seu ideal de autonomia e sua compreensão essencialmente aberta do ensino, o Estado alemão regulamentou a criação de novos tipos de escolas técnicas, as Volkshochschulen, as Fachschulen e outras instituições de ensino profissionalizante, preservando a carga simbólica exclusivamente humanista que garantiu ao Gymnasium o poder majoritário sobre a concepção de autonomia das instituições pedagógicas modernas. Tal simbolismo perpetuou-se duplamente. No horizonte das reformas educacionais que tiveram lugar durante todo o século XIX na Europa em geral, a escola secundária humanista alemã serviu de referência principal. É assim que Victor Cousin, Émile Durkheim e Mathew Arnold são apenas alguns nomes entre os que visitaram o Gymnasium a fim de reconhecer a importância dessa referência e incorporá-la nos modelos de seus países de origem (Cf. Anderson, 2004, p. 95). Em âmbito nacional, seu significado cultural foi ainda maior: o elitismo acentuado do ensino secundário alemão não impediu que ele sintetizasse, no imaginário popular, um ideal de cultura em que todos procuravam se reconhecer. Como demonstram os romances de Goethe ou de Musil, seus alunos eram frequentemente visados como a promessa futura de uma nova classe de intelectuais, capaz de levar ao resto da Europa o sucesso da cultura germânica. Ao mesmo tempo, professores ginasiais gozavam de privilégios sociais só comparáveis aos dos professores universitários e aos altos funcionários do Estado - poderiam, assim, receber o tratamento de doutor na vida pública, e, muitas vezes, por extensão, mesmo sua esposa poderia ser tratada com essa reverência.

Desde o fim da Segunda Guerra Mundial, a estrutura do Gymnasium alemão vem sendo amplamente revista, na tentativa de desvinculá-lo da forte ideia de nacionalismo que foi fomentada em seu interior desde a unificação militar em 1871 e que culminou em seu investimento institucional como polo da elite da juventude hitlerista (cf. Hartshorne Jr., 1937, p. 42 e ss.; Balder, 2006, p. 130 e ss.). Seja como for, a compreensão de autonomia elaborada pelo conceito neo-humanista de Bildung recebeu, no interior das escolas secundárias, um tratamento simbólico extremamente refinado, capaz de envolver as mais diversas camadas sociais em torno do projeto educativo, e derivou um modelo de educação continuada que teve um longo destino nos debates da pedagogia contemporânea. 
Por fim, foram as reformas referentes ao ensino superior que garantiram ao modelo alemão a amplitude de influência que ele obteve desde as primeiras décadas do século XIX. É a elas, e ao seu marco mais inequívoco, a fundação da Universidade de Berlim, que o nome de Humboldt se associa na história da educação moderna. Sua ruptura profunda, ao mesmo tempo epistemológica e institucional, com a ideia de universidade corrente na Europa de então, deriva da extensão do princípio de autonomia da Bildung, aplicado um pouco antes nos ginásios. Sob esse aspecto, a reforma universitária do neo-humanismo é, historicamente, uma consequência lógica do sucesso alcançado pelas novas estruturas de ensino da escola secundária, e o elo entre esses dois momentos da formação dos indivíduos somente se estreitou desde esse desdobramento. No entanto, a história da consolidação do ensino superior moderno na Alemanha é extremamente complexa, em função das contradições sociais que comporta, dos impasses políticos que enfrenta e das exigências institucionais erguidas em função de uma explícita e intermitente competitividade com outros modelos europeus - e, por isso, o que pretendo indicar é apenas um esboço a ser desenvolvido. O que essa história nos informa, no entanto, é fundamental: ela diz respeito à trajetória de uma ideia de autonomia cultural que procurou se equilibrar, muitas vezes, de forma precária, entre as demandas ideológicas do poder do Estado e as exigências pragmáticas da esfera privada. No Brasil, o fenômeno recente da expansão das universidades particulares, e as estratégias políticas empregadas pelo poder público para lidar com ela, envolve a investigação em torno da origem histórica desse debate com uma relevância singular.

O plano de construir uma universidade segundo as exigências de um ensino moderno e cosmopolita - e, ao mesmo tempo, genuinamente germânico - já vinha sendo pensado pelo governo de Frederico Guilherme III desde o final do século XVIII. Sua intenção declarada de rivalizar com as universidades francesas apenas acelerou esse processo. Karl Friedrich Beyme foi o funcionário do governo encarregado, em 1800, de viabilizar o projeto. Seu nome é particularmente importante aqui porque, pela primeira vez, o Estado procurou promover reformas na educação a partir do envolvimento ativo dos professores, cientistas e artistas que integravam o horizonte mais imediatamente visível da cultura alemã. Essa é uma primeira distinção importante da fundação da pedagogia moderna: as instituições culturais não devem ser mais o resultado concreto de um mecenato esclarecido, ao qual os intelectuais e todos que delas participavam precisariam se adequar, em maior ou menor medida. A condição pragmática mais incontornável do neo-humanismo é que cada uma dessas instituições tinha de ser consequência direta de uma discussão estabelecida entre aqueles que se vinculavam a elas. Uma inversão no processo de adequação que Beyme precisou negociar entre o Estado e os intelectuais. Uma das evidências do poder funcional do Gelehrter neste sentido é a solicitação que o governo fez aos principais intelectuais universitários de apresentarem, sob a forma de relatórios 
suficientemente detalhados, suas ideias do que seriam os princípios e as regras desse estabelecimento. Schleiermacher, Fichte, August Wolff e Humboldt foram alguns desses eruditos que apresentam suas propostas.

Foi o modelo proposto por este último que parece ter harmonizado de maneira mais convincente e diplomática a exigência de uma instituição de ensino superior capaz de encontrar sua finalidade em si mesma e de uma administração estatal menos intrusiva. A Universidade de Berlim é fundada, assim, em 1810, de acordo com essas premissas humboldtianas e, em duas décadas, havia se tornado a maior e mais reconhecida universidade alemã (cf. Kretschmer, 1999, p. 15-20). O relatório de Humboldt, denominado Sobre a organização interna e externa das instituições científicas superiores em Berlim, apesar de mais sucinto, por exemplo, que a proposta de Fichte, insiste, mais que qualquer outro, nesses limites do poder governamental. Na verdade, desde o primeiro parágrafo do texto, tal divisa já está inequivocamente anunciada. Ele diz:

O conceito das instituições científicas superiores deve significar, ao mesmo tempo, o ápice daquilo que é incontornável para que a cultura moral da nação surja, e que é determinado por si mesmo, [ou seja] promover a ciência, no sentido mais profundo e amplo da palavra, ${ }^{1}$ [mas esse conceito também deve se dar] como conteúdo de uma formação cultural espiritual e moral [geistige und sittliche Bildung], que não pode ser determinada por nenhuma perspectiva alheia, mas cuja utilidade deve ser deduzida apenas de si mesma. (Humboldt, 2002, p. 255)

Mais adiante, Humboldt é ainda mais sistemático e específico: entre os meios econômicos subsidiados pelo Estado para a formação da cultura por meio da universidade e o aparelho ideológico em que ele está sempre tentado a forçá-la a se tornar, é preciso estar frequentemente atento para esse equilíbrio favorável ao princípio de autonomia completa da educação (idem, ibid., p. 257).

O que o modelo conceitual da Bildung neo-humanista impõe ao seu modelo institucional de ensino superior é um projeto, tão realizável concretamente quanto possível, de autonomia administrativa das faculdades. E é exatamente esta proposta de Humboldt que é escolhida como texto-diretriz da nova Universidade de Berlim. É verdade que nem sempre esse modelo pôde encontrar seu espaço tal e qual havia sido projetado. A exigência do desinteresse acabou por parecer muito onerosa diante de uma sociedade que começava a experimentar os avanços tecnológicos do processo de industrialização, e, sob muitos aspectos, o crescimento econômico substituiu os ideais humanistas, impalpáveis, por objetivos técnicos, mais diretamente relacionados à expansão comercial da Alemanha a partir de 1850. Esse desenvolvimento, aliás, foi o que possibilitou a grande mudança que provocaria as mais diversas e inflamadas críticas que se observam no meio acadêmico contra o avanço do tecnicismo nessa época: a emergência de uma classe industrial em detrimento de uma 
significativa perda de prestígio da figura do Gelehrter fez da Bildung a palavra de ordem contra a nova ordem financeira, como mostram os jornais mais tradicionalistas do período. $\mathrm{O}$ afastamento entre formação cultural e crescimento econômico promoveu, assim, uma polarização que teve longo destino no imaginário da sociedade europeia, e outro ainda maior nas sociedades economicamente dependentes desta: de um lado, o intelectual guardava consigo a herança espiritual da cultura do Ocidente, do outro, o comerciante burguês insistia em manipular esse legado a fim de extrair dele seu lucro. A incisiva crítica de Adorno à indústria cultural é, neste sentido, a síntese mais acabada, e típica do século XX, desse diagnóstico de descontentamento com a trajetória histórica, ou antes, com os desvios do projeto cultural humboldtiano, com os quais ainda estamos lidando. Recompatibilizar a autonomia da educação com os interesses privados, que no capitalismo das últimas décadas substituíram o poder estatal, é a retomada de um problema que a pesquisa histórica deve enviar às suas origens alemãs.

O que esta pesquisa nos ensina é que o modelo germânico, que fascinou a Europa por mais de um século, não pode ser encarado, como muitas vezes foi por uma certa vertente materialista da história, como um projeto teórico. É inegável que o simbolismo extremamente romântico desse modelo muitas vezes procurou promover medidas completamente inviáveis no horizonte cotidiano da sociedade alemã. Mas isso não foi uma exclusividade sua - basta termos em mente os desmandos nada razoáveis dos líderes da Revolução Francesa, quando, por exemplo, quiseram instituir nas escolas uma religião racionalista, que, inclusive, promulgava um novo panteão de deuses e deusas. Além disso, o modelo germânico esteve longe de ter uma aceitação hegemônica. Resguardados os óbvios distanciamentos, pode-se dizer que um grupo de eruditos ideologicamente coeso, vindo de outros países para visitar as instituições de ensino na Alemanha, indicou, entre 1850 e 1890, os sintomas de uma "época decadente e de esterilidade" (Ringer, 2000, p. 293). O descontentamento da elite cultural alemã parecia ter se tornado tão evidente que, mesmo uma série de universitários franceses - entre eles Émile Durkheim - que ali procuraram um modelo que pudesse inspirar a reforma pedagógica francesa, então em questão, não podia deixar de fazer eco às suas críticas. Ainda que tenham adotado, mais tarde, $\mathrm{o}$ modelo alemão do professor-pesquisador, não escapava aos franceses o que thes pareceu os três grandes problemas das escolas na Alemanha: a falta de uma administração centralizadora, a expansão de uma elite pouco integrada aos reais interesses de um progresso científico e a vinculação de fatores econômicos à escolha dos cursos a serem cursados pelos jovens estudantes (cf. Charle, 1994, p. 21-59).

Mas o simbolismo da pedagogia de Humboldt só pôde se incorporar a outras culturas e se universalizar porque era indissociável de uma série de exigências práticas. Somente assim podemos entender como o viés definitivamente romântico 
dessa concepção de autonomia da formação dos indivíduos, que propunha também a cultura pela cultura, assim como a ciência pela ciência e a arte pela arte, atravessou praticamente todos os modelos de educação liberal do século XX, chegando até nós sob a forma de um imperativo ético cada vez mais refinado pelas exigências positivas e pragmáticas do multiculturalismo. Positiva e negativamente, a transdisciplinaridade das faculdades de educação nas universidades brasileiras, sensivelmente mais ampla que qualquer modelo europeu, pode ser entendida a partir da radicalização desse princípio, e é, portanto, uma consequência, ainda que bastante indireta, das prerrogativas políticas da pedagogia neo-humanista alemã. Não me refiro aqui apenas à influência que as observações de Georges Gusdorf e Jean Piaget sobre a necessidade de se pensar a tarefa das ciências como um trabalho coletivo exerceram na consolidação do pensamento educacional brasileiro - a partir das reflexões de Hilton Japiassú e, mais recente e especificamente, de Ivani Fazenda (cf. Fazenda, 1994, p. 19 e ss; Thiesen, 2008, p. 545). Uma recensão crítica das repercussões mais contemporâneas desta influência, questionando seus limites em relação à sua trajetória, nos é fornecida pelo livro Pesquisa em educação, de Zaia Brandão (cf. Brandão, 2002, p. 45-60). A ideia de transdisciplinaridade a que me refiro aqui pode ser lida como uma maneira mais ampla de pensar os problemas da taxonomia do conhecimento nos quadros dos projetos pedagógicos, que se acentuou no horizonte das ciências humanas já desde a década de 1930 - com os trabalhos de Norbert Elias e Marc Bloch, especialmente -, quando disciplinas como sociologia, história, filosofia e antropologia passaram por um processo de ampla reformulação fundamentado no diálogo que poderiam estabelecer entre si (cf. Lattuca, 2002, p. 711-712). Na verdade, o desconforto com o caráter de especialização das disciplinas acadêmicas já havia marcado profundamente as propostas pedagógicas à época do neo-humanismo, e o próprio Humboldt já insistia na ideia de que a universidade deveria "produzir e preservar uma colaboração contínua entre cientistas de diferentes disciplinas" (Humboldt, 2002, p. 256). Ora, uma tal insatisfação alimentava os intelectuais que formaram o grupo conhecido como os pioneiros da Educação Nova no Brasil muito antes de Piaget, Gusdorf ou Bourdieu. Seu conhecido Manifesto, de 1930, não apenas determina que o educador "tem necessidade de uma cultura múltipla e bem diversa", como também articula esta exigência com a premissa de que os fins da educação dependem de um espírito científico que "empregará os methodos communs e todo gênero de investigação scientifica" (Manifesto, apud Ghiraldelli, 1994, p. 55).

É precisamente em função disso que a história do neo-humanismo como história de um modelo pedagógico crítico e universalizado pode nos fornecer elementos conceituais para uma revisão efetiva de nosso projeto de educação. A exigência de se ampliar o raio de ação das instituições culturais nos processos de formação dos indivíduos, assim como a emergência do tipo social do professor-pesquisador, 
são apenas dois sintomas de uma nova direção na agenda política da educação no Brasil. A pesquisa histórica informa-nos que essa direção nos leva ao encontro de Humboldt. E a tarefa que ela nos impõe, concomitantemente, é a de sondar sob que termos específicos podemos resgatar nossa tardia e equívoca fraternidade com Werther e Törless.

\section{Nota}

1. Vale lembrar aqui que o termo empregado por Humboldt é Wissenschaft, que tem um sentido muito mais amplo que a ciência adquiriu como técnica ao longo do século XX.

\section{Referências}

ALLEN, A.T. Gardens of children, gardens of god: kindergartens and day-care centers in nineteenth-century Germany. Journal of Social History, Pittsburgh, v. 19, n. 3, p. 433-50, 1986.

ANDERSON, R. The idea of the secondary school in Nineteenth-Century Europe. Paedagogica Historica, Gent, v. 40, n. 1/2, p. 93-106, 2004.

BALDER, H.-G. Geschichte des Deutschen Burschenschaft. Hilden: WJK, 2006.

BRANDÃO, Z. Pesquisa em educação: conversas com pós-graduandos. Rio de Janeiro: PUC-Rio, 2002.

CHARLE, C. La république des universitaires 1870-1940. Paris: Seuil, 1994.

EYCK, F.G. The political theories and activities of the German academic youth between 1815 and 1819. The Journal of Modern History, Chicago, v. 27, n. 1, p. 27-38, 1955.

FAZENDA, I.C.A. Interdisciplinaridade: história, teoria e pesquisa. Campinas: Papirus, 1994.

GHIRALDELLI, P.J. História da educação. 2. ed. São Paulo: Cortez, 1994.

GOETHE, J.W. Leiden des jungen Werthers. In: GOETHE, J.W. Sämmtliche Werke in dreissig Bänden. Stuttgart; Tübingen: Cotta, 1850-1851.

HARTSHORNE JR., E.Y. The German universities and national socialism. London: George Allen \& Unwin, 1937.

HOLBORN, H. A history of modern Germany, 1648-1840. New Jersey: Princeton University, 1964. 
HUMBOLDT, W. Ideen zu einen Versuch, die Gränzen der Wirksamkeit des Staats zu bestimmen. In: HUMBOLDT, W. Gesammelte Werke. Berlin: B. Behr's, 1903. v. 7.

HUMBOLDT, W. Ueber die innere und äussere Organisation der höheren wissenschaftlichen Anstalten in Berlin. In: HUMBOLDT, W. Werke in fünf Bänden: Schriften zur Politik und zum Bildungswesen. Stuttgart: Cotta, 2002. v. 4.

KRETSCHMER, J. Introdução. In: FICHTE, J.G. Por uma universidade orgânica. Rio de Janeiro: Uerj, 1999.

LATTUCA, L. Learning interdisciplinarity: sociocultural perspectives on academic work. Journal of Higher Education, Columbus, v. 73, n. 6, p. 711-739, 2002.

MASSEAU, D. L'invention de l'intellectuel dans l'Europe du XVIIIe siècle. Paris: PUF, 1995.

MONTAIGNE, M. Ensaios: livro I. São Paulo: Martins Fontes, 2000.

MUSIL, R. O jovem Törless. Rio de Janeiro: Nova Fronteira, 1981.

RINGER, F. O declínio dos mandarins alemães: a comunidade acadêmica alemã, 18901933. São Paulo: Edusp, 2000.

THIESEN, J.S. A interdisciplinaridade como um movimento articulador no processo ensino-aprendizagem. Revista Brasileira de Educação, Rio de Janeiro, v. 13, n. 39, p. 545-554, 2008.

Recebido em 26 de junho de 2009.

Aprovado em 23 de junho de 2010. 